\title{
Single Stator Dual PM Rotor Synchronous Machine with two- frequency single-inverter control, for the propulsion of hybrid electric vehicles
}

\author{
Marcel Topor ${ }^{1}$, Fabrizio Marignetti ${ }^{2}$, Sorin Ioan Deaconu ${ }^{1}$, and Lucian Nicolae Tutelea ${ }^{1}$ \\ ${ }^{1}$ Politechnica University of Timisoara, Electrical Engineering Department \\ ${ }^{2}$ University of Cassino, Electrical Engineering Department
}

\begin{abstract}
This paper introduces a novel brushless, single winding and single stator, dual PM rotor axialair-gap machine capable to deliver independently torque at the two rotors by adequate dual vector control. The proposed topologies, the circuit model, controlled dynamics simulation and preliminary 3D FEM torque production on a case study constitute the core of the paper. The proposed dual mechanical port system should be instrumental in parallel (with planetary gears) or series hybrid electric vehicles (HEV) aiming at a more compact and efficient electric propulsion system solution.
\end{abstract}

\section{Introduction}

Vehicles equipped with internal combustion engine (ICE) have been in existence for over a hundred years. Although ICE vehicles (ICEVs) are being improved by modern automotive electronics technology, they need a major change to significantly improve the fuel economy and reduce the emissions [1].

Electric vehicles (EVs) and hybrid EVs (HEVs) have been identified to be the most viable solutions to fundamentally solve the problems associated with ICEVs [2]-[4]. Electric drives are the core technology for EVs and HEVs [5]-[10].

A key problem with $\mathrm{HEV}$ is the electric propulsion corroboration with the thermal engine traction (ICE) such that the latter is allowed to operate close to the sweet point (torque and speed for maximum efficiency or minimum emission) indifferent to the vehicle speed [11]-[12].

A so called continuously variable transmission (CVT) is required for the scope.

The Toyota Prius e-CVT solution for the parallel HEV requires two electric machines, two inverters, and a planetary gear [1].

A distinct electric generator and a propulsion electric motor, both with full power converters, are typical for a series HEV.

The present paper proposes a new, dual PM rotor, SM drive with basically single a stator and dual rotor with different pole counts and high winding factors, to reduce volume, weight and cost in either planetary-gear parallel HEV or in series HEV. The paper is organized as follows: Section 2: proposed dual PM rotor machine topology, Section3: the dual PM rotor single stator phase coordinate model, Section 4: 3D FEM torque production analysis, Section 5: proposed dual two- frequency vector control and dynamic simulations, Section 6: conclusions.

\section{The proposed dual PM rotor machine topology}

In an effort to simplify the planetary-geared e-CVT for the parallel HEV or the series HEV we hereby propose to replace the basically two electric machines and their two power converters by a single, axial-air-gap, electric machine central stator, fed from a single PWM converter with dual frequency voltage output $\left(\mathrm{V}_{1}\left(\mathrm{f}_{1}\right), \mathrm{V}_{1}\left(\mathrm{f}_{2}\right)\right)$ and two independent PM rotors with $2 \mathrm{p}_{1}$ and $2 \mathrm{p}_{2}$ poles, placed on the sides of the central stator provided with $\mathrm{N}_{\mathrm{s}}$ slots and a tooth-wound (or Gramme) winding (Fig. 1).

The mixture of two frequencies in the inverter output voltage (with corresponding phase angles) leads to two different speeds $\omega_{\mathrm{r} 1}$ and $\omega_{\mathrm{r} 2}$ in the two rotors and different positive (or negative) torques, as required.

The two frequency voltages and their currents travel the whole single stator winding coils sides, though only the left side (in fig. 1) produces torque at $\omega_{\mathrm{r} 1}$ speed and only the right side interacts to produce torque at $\omega_{\mathrm{r} 2}$ speed.

This implies some additional copper losses in the stator but if the end connections are kept small, part of this inconveniency is removed.

On the other hand, the single inverter has to handle the entire apparent power related to the interaction of stator magnetic fields with both rotors at different speeds.

Only when the two frequencies are equal to each other and electric rotor speeds related by $\omega_{\mathrm{r} 1}=\omega_{\mathrm{r} 2}\left(\mathrm{n}_{1} \mathrm{p}_{1}\right.$ $=\mathrm{n}_{2} \mathrm{p}_{2}$ ), a direct transfer of power through the winding,

* Corresponding author: sorin.deaconu@fih.upt.ro

(C) The Authors, published by EDP Sciences. This is an open access article distributed under the terms of the Creative Commons Attribution License 4.0 (http://creativecommons.org/licenses/by/4.0/). 
for say, one motoring and one generating operation modes, seems to be possible.

Apart from the evident simplification and compactness of the proposed solution, attempts to reduce somewhat the inverter power rating based on motor/generator simultaneity are worth trying (for medium speeds one rotor is less active).

Though there will be $\omega_{2}-\omega_{1}$ torque pulsations from one rotor to the other, the torque stress on the stator will be reduced when one rotor is motoring and one is generating.

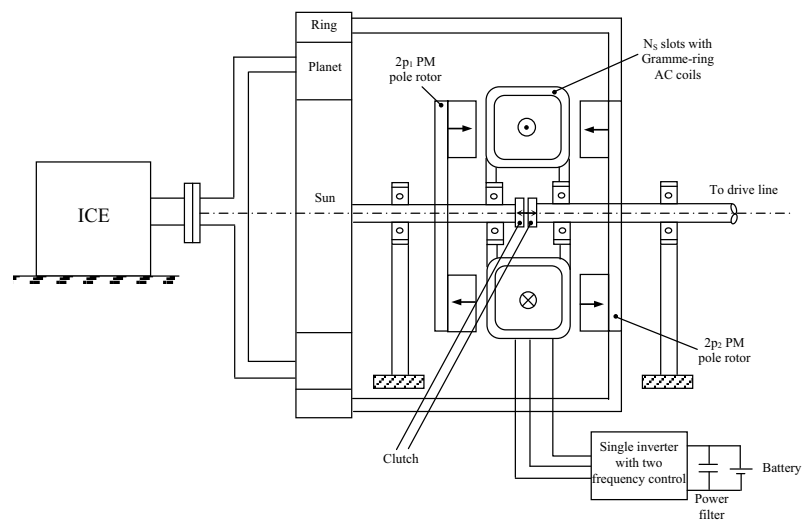

a)

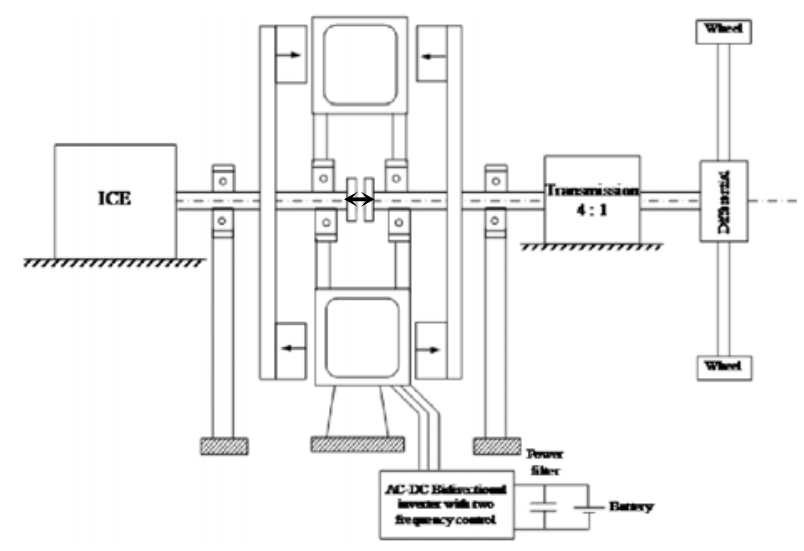

b)

Fig. 1. Proposed e-CVT with single electric machine stator and single inverter a) for planetary gear parallel HEV; b) for series, HEV.

The proposed e-CVT topology in detail is presented in figure 2 .

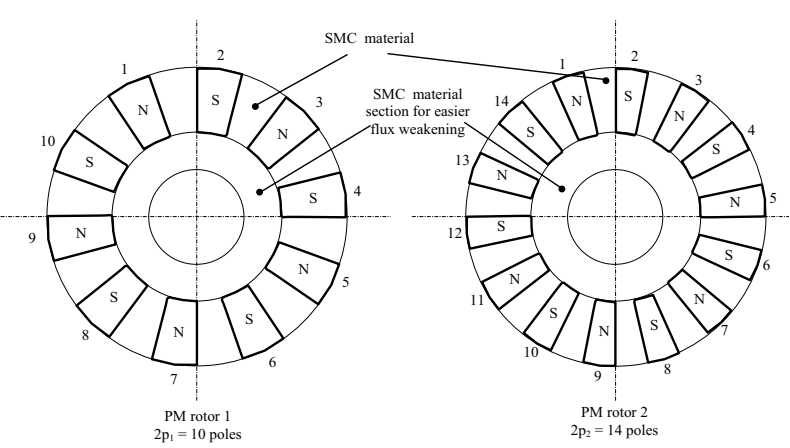

a)

b)

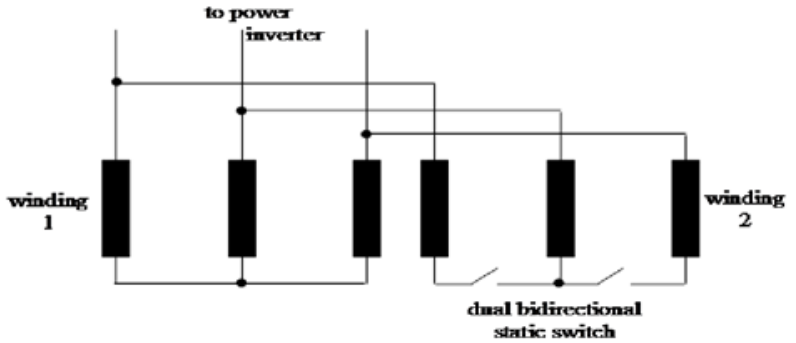

c)

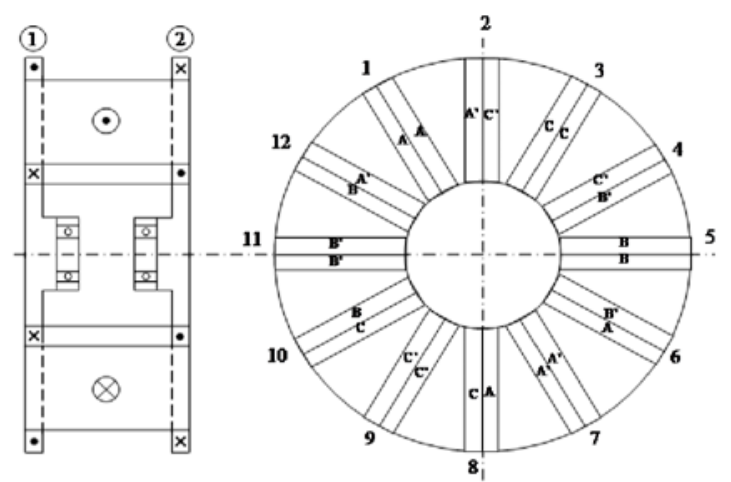

d)

Fig. 2. Dual PM rotor (10 poles/14 poles) axial air-gap single stator (12 slots) PMSM proposed typical topology:

a) 10 PM poles rotor with SMC back iron and small-air-gap SMC zone for flux weakening; b) 14 PM poles rotor with SMC back iron; c) SMC stator with machined slots and Gramme ring ("through") AC coils; d) opening half of the winding in fig. 4e; e) two layers "non-through" coil winding.

Though fig. 2 is rather self-explanatory, here are few remarks:

- the stator core magnetic circuit SMC material is suggested, but a rolled-lamination magnetic core is also feasible, especially for the case of "non through" coils (fig.2e); the same rationale is valid for the rotor magnetic core.

- either "through" or "non through" coil shapes may be adopted; it seems that if the number of turns/coil is small, "non through" coils may be mounted easily.

- it may be, however, possible to adopt double layer coils along tangential direction with opposite polarity on the two stator axial sides (fig. 2d). In this case a dual TRIAC switch might be used to disconnect one half winding when only motoring or only generating is needed, with only one rotor being active (typical to average vehicle speeds).

The stator m.m.f. flux lines in the stator close circumpherentially in the back iron and thus avoid severe flux fluctuations in the two rotors; besides, the PM flux fluctuation effects from one rotor to the other $\left(2 \mathrm{p}_{1} \neq\right.$ $2 \mathrm{p}_{2}$ ), should be small for surface PMs, for the same reason.

The axial flux permanent machines with double rotor and single stator have smaller axial length than the corresponding solution with radial flux, for given, larger than 6 , number of poles and diameter, as it is mentioned in both references [13-14].

Figure 3 shows the two rotors with different number of permanent magnet poles. The different number of 
poles may impose a rather different amount of permanent material but if we select the arc pole ratio adequately, it is possible to use the same amount of permanent magnet material in both rotors.

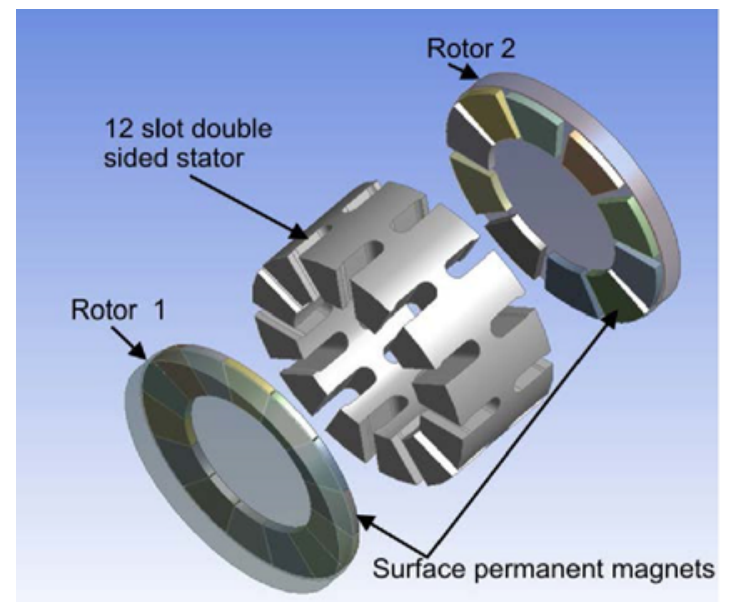

Fig. 3. Proposed configuration exploded view

\section{The proposed phase-coordinate model}

The stator phase supply voltages $\mathrm{V}_{\mathrm{s}}$ a $\mathrm{b}$ c contain two frequencies

$$
\begin{aligned}
& \mathrm{V}_{\mathrm{sabc}}=\mathrm{V}_{\mathrm{s}_{1}}^{*} \cos \left(\theta_{\mathrm{er}_{1}}+\gamma_{1}\right)+\mathrm{V}_{\mathrm{s}_{2}}^{*} \cos \left(\theta_{\mathrm{er}_{2}}+\gamma_{2}\right), \\
& \frac{\mathrm{d} \theta_{\mathrm{er}_{1}}}{\mathrm{dt}}=\omega_{\mathrm{r}_{1}}, \quad \frac{\mathrm{d} \theta_{\mathrm{er}_{2}}}{\mathrm{dt}}=\omega_{\mathrm{r}_{2}}, \\
& \gamma_{1}=\frac{\pi}{2}+\delta_{\mathrm{v}_{1}}, \quad \gamma_{2}=\frac{\pi}{2}+\delta_{\mathrm{v}_{2}},
\end{aligned}
$$

where $\delta_{\mathrm{v} 1}, \delta_{\mathrm{v} 2}$ are the voltage power angles (positive for motoring, negative for generating); $\theta_{\mathrm{er} 1}, \theta_{\mathrm{er} 2}$ rotors 1 and 2 electrical position angles (PM rotor axes).

The small SMC rotor pole parts (with some anisotropy) (Fig. 2a) are used to facilitate PM flux weakening and also (by proper pole span segmentation), to facilitate rotor position estimation in case of sensorless control.

Let us neglect here the small rotor saliency (left in the rotors SMC pole section, for easier flux weakening) and discuss here the Gramme ring winding case. The total phase inductance $\mathrm{L}_{\mathrm{S}}$ and resistance $\mathrm{R}_{\mathrm{S}}$ (considering both rotors with all phase coils in series), though different, are rather straightforward (as for constant airgap AC machines):

$$
\begin{aligned}
& \mathrm{L}_{\mathrm{S}} \cong 6 \cdot \frac{\left(\mathrm{N}_{\mathrm{S}} \cdot \mathrm{n}_{\mathrm{c}} \cdot \mathrm{k}_{\mathrm{w1}} / 3\right)}{\pi^{2} \cdot \mathrm{g}_{\mathrm{m}}\left(1+\mathrm{k}_{\mathrm{S}}\right) \cdot \mathrm{k}_{\mathrm{c}}} \cdot\left[\frac{\left(1+\mathrm{k}_{\text {diff } 1}\right)}{\mathrm{p}_{1}}+\frac{\left(1+\mathrm{k}_{\text {diff } 2}\right)}{\mathrm{p}_{2}}\right]+\mathrm{L}_{\mathrm{ls}}+\mathrm{L}_{\mathrm{lEC}}, \\
& \mathrm{R}_{\mathrm{S}}=\rho_{\mathrm{co}} \cdot \frac{\left(\mathrm{N}_{\mathrm{S}} \cdot \mathrm{n}_{\mathrm{c}} / 3\right) \cdot \mathrm{c}_{\text {coil }}}{\mathrm{I}_{\text {rated }}} \cdot \mathrm{j}_{\text {co rated }}, \mathrm{g}_{\mathrm{m}}=\mathrm{g}+\mathrm{h}_{\mathrm{PM}},
\end{aligned}
$$

$\mathrm{L}_{\mathrm{ls}}$ - slot leakage inductance;

$\mathrm{L}_{\mathrm{IEC}}$ - end connection inductance;

$\rho_{\text {co }}-$ copper resistivity;

$\mathrm{N}_{\mathrm{S}}$ - number of stator slots;

$\mathrm{n}_{\mathrm{c}}-$ number of turns/coil;

$1_{\text {coil }}$ - turn length;

$\mathrm{g}$ - mechanical gap;

$\mathrm{h}_{\mathrm{PM}}-\mathrm{PM}$ axial thickness;

$\mathrm{j}_{\text {co rated }}$ - rated copper current density;

$\mathrm{I}_{\text {rated }}$ - rated current;

$\mathrm{k}_{\mathrm{w} 1}$-fundamental winding factor: 0.933 for the 12

slots/10 pole and for 12 slots /14 poles configurations;

$\mathrm{k}_{\text {diff } 1,2}$ - differential leakage inductance coefficients for the rotor with $2 \mathrm{p}_{1}$ and, respectively, $2 \mathrm{p}_{2}$ poles (which we know are large in tooth-wound windings because the stator m.m.f. is rich in space harmonics).

The e.m.f. per phase, produced by PMs is:

$$
\begin{aligned}
& \mathrm{E}_{1,2 \mathrm{abc}}=\omega_{\mathrm{r} 1,2} \cdot \varphi_{\mathrm{PM} 2 \mathrm{p}_{1}\left(2 \mathrm{p}_{2}\right)} \cdot \mathrm{k}_{\mathrm{w} 1} \cdot \frac{\mathrm{N}_{\mathrm{S}}}{6} \cdot \mathrm{n}_{\mathrm{c}} \cdot \\
& \cdot \cos \left[\theta_{\mathrm{er} 1,2}-(\mathrm{i}-1) \frac{2 \pi}{3}+\frac{\pi}{2}\right]
\end{aligned}
$$

With $\left|L_{S}\right|$ a diagonal matrix with constant terms, the matrix stator voltage equations are straight forward:

$$
\begin{aligned}
& \left|i_{a b c} \cdot R_{S}\right|-\left|V_{a b c}\right|=-L_{S} \frac{d}{d t}\left|i_{a b c}\right|-\left|E_{1 a b c}+E_{2 a b c}\right|, \\
& \frac{J}{p_{1}} \cdot \frac{d \omega_{r 1}}{d t}=\frac{p_{1}}{2} \cdot \frac{\left(E_{1 a} \cdot i_{a}+E_{1 b} \cdot i_{b}+E_{1 c} \cdot i_{c}\right)}{\omega_{r 1}}-T_{1 \text { load }},(6) \\
& \frac{J}{p_{2}} \cdot \frac{d \omega_{r 2}}{d t}=\frac{p_{2}}{2} \cdot \frac{\left(E_{2 a} \cdot i_{a}+E_{2 b} \cdot i_{b}+E_{2 c} \cdot i_{c}\right)}{\omega_{r 2}}-T_{2} \text { load }
\end{aligned}
$$

This circuit model has been developed for controlled dynamics investigation as only a full 3D Finite Element Analysis (FEA) can accurately analyze the complex geometry of the proposed electric machine.

\section{3D FEM Analysis For Torque Production}

The main purpose of this analysis is to find out torque in the proposed axial flux machine using 3D field analysis method. The main parameters of the model are given in table 1.

A full scale model using commercial software was built for the 3D nonlinear magneto-static solution. Using the full scale model with an average mesh of 500000 nodes, the flux density solution was obtained.

Figure 4 shows the PM air-gap flux density of the machine. It can be seen from the plot that maximum airgap flux density is nearly $0.8 \mathrm{~T}$ and the average air-gap flux density is $0.55 \mathrm{~T}$, at mean diameter.

It can also be noted from the air-gap flux density plot that the flux density becomes greater at the edges of the magnets because of the fact that the leakage flux between the magnets gains importance and causes some 
concentration of flux (shorter than pole-pitch wide PMs might overcome this difficulty).

Table 1. Parameters and machine dimensions.

\begin{tabular}{|l|c|}
\hline Frequency $(\mathrm{f})$ & $50 \mathrm{~Hz}$ \\
\hline Number of poles rotor $1\left(2 \mathrm{p}_{1}\right)$ & 10 poles \\
\hline Number of poles rotor $2\left(2 \mathrm{p}_{2}\right)$ & 14 poles \\
\hline Current density $(\mathrm{Js})$ & $4.33 \mathrm{~A} / \mathrm{mm} 2$ \\
\hline Air-gap length $(\mathrm{g})$ & $1 \mathrm{~mm}$ \\
\hline Pole-arc-ratio rotor $1\left(\alpha_{\mathrm{i} 1}\right)$ & 0.6944 \\
\hline Pole-arc-ratio rotor $2\left(\alpha_{\mathrm{i} 2}\right)$ & 1 \\
\hline Outer diameter $\left(\mathrm{D}_{\mathrm{o}}\right)$ & $300 \mathrm{~mm}$ \\
\hline Inner diameter $\left(\mathrm{D}_{\mathrm{i}}\right)$ & $180 \mathrm{~mm}$ \\
\hline Slot depth $\left(\mathrm{h}_{\mathrm{ss}}\right)$ & $30 \mathrm{~mm}$ \\
\hline Axial length of stator core $\left(\mathrm{h}_{\mathrm{cs}}\right)$ & $90 \mathrm{~mm}$ \\
\hline Axial length of rotor core $\left(\mathrm{h}_{\mathrm{cr}}\right)$ & $10 \mathrm{~mm}$ \\
\hline Magnet axial length $\left(\mathrm{h}_{\mathrm{PM}}\right)$ & $5 \mathrm{~mm}$ \\
\hline Permanent magnet material & $\mathrm{NeFeBr} 40$ \\
\hline
\end{tabular}

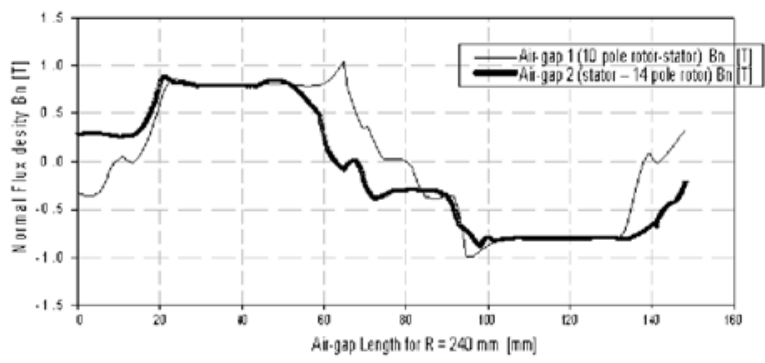

Fig. 4. No load air-gap flux density variation from finite element analysis.

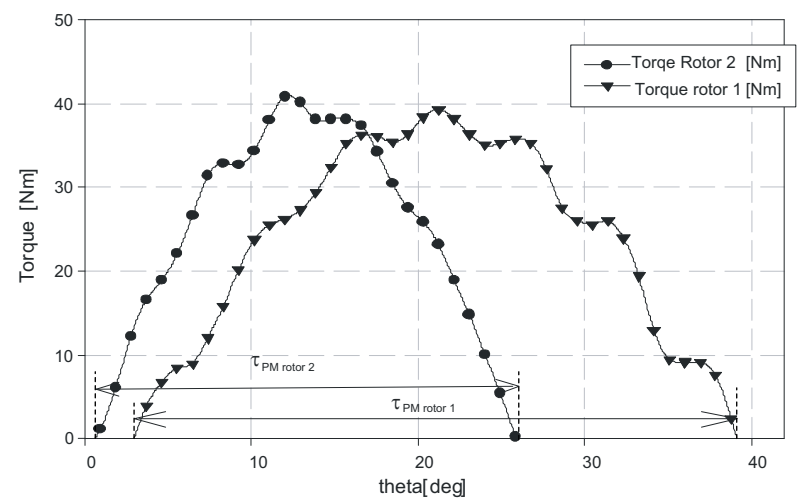

Fig. 5. Torque obtained from 3D FEM magnetostatic analysis for the two rotors.

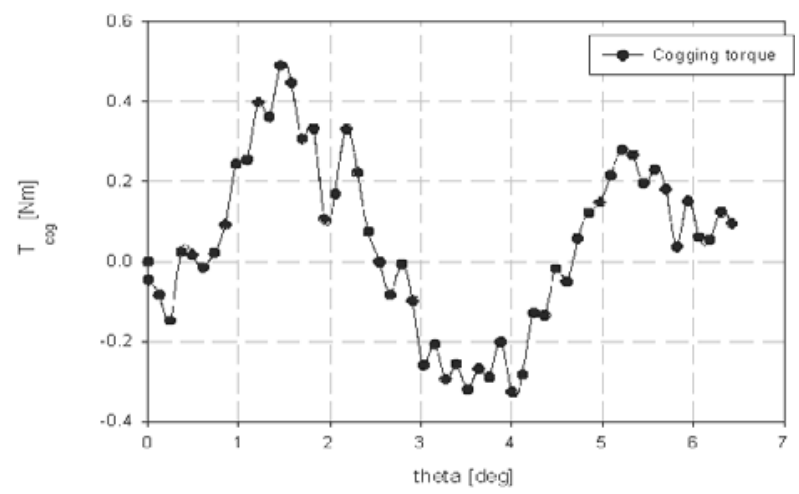

Fig. 6. Cogging torque from $3 \mathrm{D}$ analysis.
In general, the total torque of a PM machine is characterized by cogging torque, average torque and onload (total) ripple torque. Since the considered prototype has a slotted topology, the pulsating torque comprises both cogging and on-load ripple torque components.

The two output torques at zero speed for constant amperturns (3744 dc Aturns per slot) is presented in fig 5 . The torque for each rotor was computed separately by means of Maxwell stress tensor.

As the calculations in fig. 5 have been done at standstill, with DC currents, the torque pulsations created by one frequency voltage in both rotors do not occur.

The cogging torque may affect the torque quality of the permanent magnet machines. In our case the two rotors are decoupled from each other. We have analyzed the cogging torque by rotating the two rotors simultaneously and we have evaluated the torque in the central stator. The resulting cogging torque presented in figure 6 is the summation of the two cogging torques produced by the two rotors, which, obviously do not overlap. It is however fairly small.

\section{Proposed Dual Vector Control Strategy and Dynamic Simulation}

The proposed dual (two-frequency) vector control strategy is illustrated in fig. 7, for the speed control mode.

The objective of the dynamic simulation is to evaluate the dynamic and steady state operation of the dual vector control algorithm using two frequency modulation operation.

Fig. 7 illustrates in fact an indirect DC current control vector control strategy with open loop (voltage) PWM strategy after rotor coordinate transformations back and forth to $\omega_{\mathrm{r} 1}$ and $\omega_{\mathrm{r} 2}$.

The PI + SM (sliding mode) speed and current controllers (with chattering elimination by the addition of a PI signal, applied to the sliding mode functional, which is active only close to the target) provide for robust control, without e.m.f. compensation, so usual with DC current regulators.

Based on the machine circuit model in paragraph 3, the dual vector control strategy dynamic behavior is simulated here via a dedicated Matlab Code. The complete set of parameters (obtained by trial and error) used in simulations are given in table 2 .

The case evaluated is the drive startup behavior for rotor 2 with the speed ramping from 0 to $1000 \mathrm{rpm}$ at no load and a step load of $15 \mathrm{Nm}$ at $\mathrm{t}=1 \mathrm{~s}$. Rotor 1 is driven by the IC engine in controlled generator mode $(-30 \mathrm{~N} \cdot \mathrm{m})$ (Fig. 8a, b, c).

Fig. $8 \mathrm{a}$ is presenting the stator current for the startup of rotor 2 and the machine $15 \mathrm{Nm}$ step load which occurs at $1 \mathrm{~s}$ from startup. The torque for rotor 2 at startup and step load is shown in figure $8 \mathrm{~b}$ and negative (generating) torque of rotor 1 in fig.8c. The torque pulsations (of the two frequency m.m.f.s. in the two rotors) are mild in this particular case but not so in for all situations. 
Table 2. Dual vector control drive system parameters.

\begin{tabular}{|c|c|c|c|}
\hline & & Phase Resistance & $2.87 \Omega$ \\
\hline & & Phase inductance & $8.50 \mathrm{E}-003 \mathrm{H}$ \\
\hline & & Rotor PM flux 1 & $0.18 \mathrm{~Wb}$ \\
\hline & & \begin{tabular}{|l|} 
Rotor PM flux 2 \\
\end{tabular} & $0.13 \mathrm{~Wb}$ \\
\hline$\div$ & & Pole pairs rotor 1 & 5 \\
\hline$\underline{\Xi}$ & & Pole pairs rotor 2 & 7 \\
\hline ت & & $\begin{array}{l}\text { Inertia (including } \\
\text { reduction of } \\
\text { translating mass) }\end{array}$ & $0.018 \mathrm{kgm}^{2}$ \\
\hline & & Power (rotor 1) & $2.5 \mathrm{~kW}$ \\
\hline & & Power (rotor 2) & $1.7 \mathrm{~kW}$ \\
\hline & & Snubber resistance & $1.00 \mathrm{E}+005 \Omega$ \\
\hline 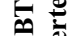 & & Ron & $2.00 \mathrm{E}-004 \Omega$ \\
\hline & & $\mathrm{Tf}$ & $1.00 \mathrm{E}-006 \mathrm{~s}$ \\
\hline & & $\mathrm{Tt}$ & $2.00 \mathrm{E}-006 \mathrm{~s}$ \\
\hline & F & Kp speed & 1 \\
\hline & $\stackrel{\Leftrightarrow}{=}$ & Ki speed & 11 \\
\hline 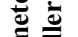 & 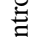 & Kp current & 0.06 \\
\hline & 8 & Ki current & 0.3 \\
\hline$\overline{0}$ & $N$ & Kp speed & $\frac{1}{1}$ \\
\hline 0 & $\stackrel{\varrho}{=}$ & Ki speed & 5 \\
\hline & E & Kp current & 0.06 \\
\hline & $\bar{\Xi}$ & Ki current & 0.3 \\
\hline
\end{tabular}

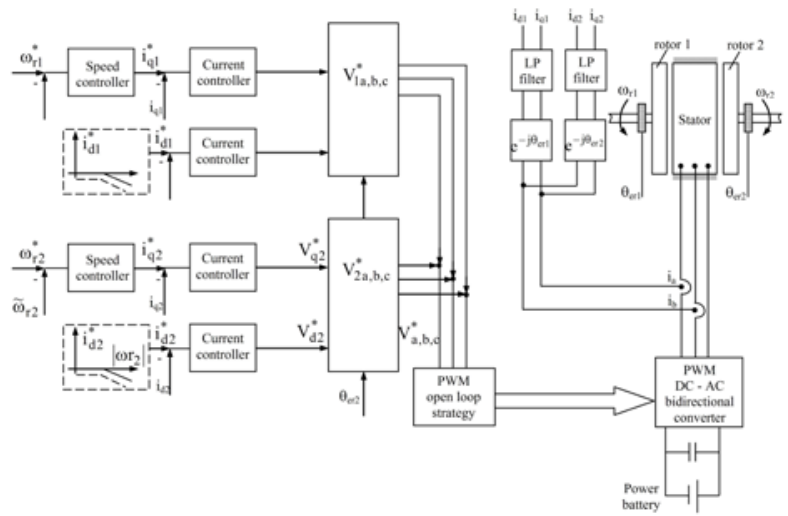

Fig. 7. Generic dual vector control strategy.

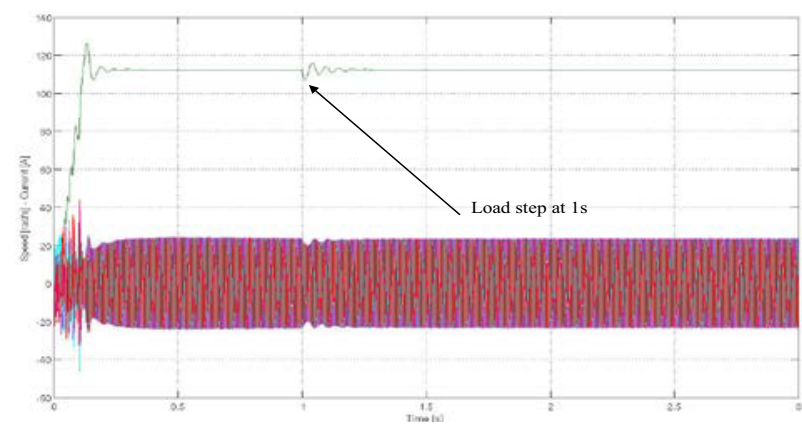

a) Rotor 2 speed for startup (0 -110rad/s) with load variation (from no load to $15 \mathrm{Nm}$ ) at $1 \mathrm{~s}$ and three phase currents.

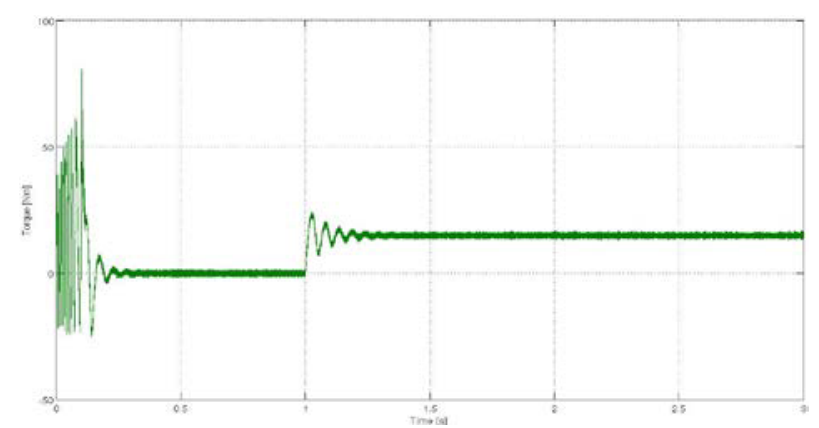

b) Torque of rotor 2 operating motor mode

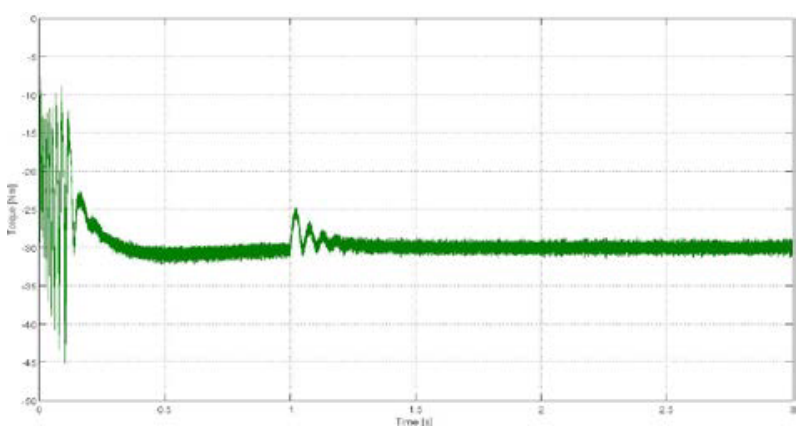

c) Torque of rotor 1 operating in generator mode at $1500 \mathrm{rpm}$. Fig. 8.

\section{Conclusions}

In this paper, a drive system to produce dual, independent, electromechanical torque output using an axial-air-gap machine with a single stator and winding and two different PM rotors has been introduced in terms of topologies, circuit model, control method (from a single inverter), and preliminary 3D-FEM torque production analysis.

Rather extended steady state and dynamics simulations have been proposed. The dual vector control for the independent rotors with one common stator is presented and proven to be effective.

These preliminary results prove the concept quantitatively but further studies, which are already under way, in relation to prototyping, dynamic model, and control and optimization design are needed to fully prove the eventual practicality of the proposed system.

\section{References}

1. K.T. Chau, C.C. Chan, C. Liu, Overview of PM brushless drives for electric and hybrid electric vehicles, IEEE Transactions on IE, vol. 55, no. 6, June 2008, pp. 2246-2257 (2008).

2. C. C. Chan and K. T. Chau, Modern Electric Vehicle Technology, Oxford, U.K.: Oxford Univ. Press, (2001).

3. M. Ehsani, K. M. Rahman, and H. A. Toliyat, Propulsion system design of electric and hybrid vehicles, IEEE Trans. Ind. Electron., vol. 44, no. 1, pp. 19-27, Feb. (1997).

4. K. T. Chau and C. C. Chan, Emerging energy-efficient technologies for hybrid electric vehicles, Proc. IEEE, vol. 95, no. 4, pp. 821-835, Apr. (2007).

5. C. C. Chan and K. T. Chau, An overview of power electronics in electric vehicles, IEEE Trans. Ind. Electron., vol. 44, no. 1, pp. 3-13, Feb. (1997).

6. Z. Q. Zhu and D. Howe, Electrical machines and drives for electric, hybrid and fuel cell vehicles, Proc. IEEE, vol. 95, no. 4, pp. 746-765, Apr. (2007).

7. M. Terashima, T. Ashikaga, T. Mizuno, K. Natori, N. Fujiwara, and M. Yada, Novel motors and controllers for high-performance electric vehicle 
with four in-wheel motors, IEEE Trans. Ind. Electron., vol. 44, no. 1, pp. 28-38, Feb. (1997).

8. K. T. Chau and Y. S. Wong, Hybridization of energy sources in electric vehicles, Energy Convers. Manag., vol. 42, no. 9, pp. 1059-1069, Jun. (2001).

9. K. T. Chau and Y. S. Wong, Overview of power management in hybrid electric vehicles, Energy Convers. Manag., vol. 43, no. 15, pp. 1953-1968, Jun. (2002).

10. M. Ehsani, Y. Gao, S. E. Gay, and A. Emadi, Modern Electric, Hybrid Electric, and Fuel Cell Vehicles: Fundamentals, Theory, and Design, Boca Raton, FL: CRC Press, (2005).

11. C. C. Chan, K. T. Chau, J. Z. Jiang,W. Xia, M. Zhu, and R. Zhang, Novel permanent magnet motor drives for electric vehicles, IEEE Trans. Ind. Electron., vol. 43, no. 2, pp. 331-339, Apr. (1996).
12. J. M. Miller, Hybrid electric vehicle propulsion system architectures of the e-CVT type, IEEE Trans. Power Electron., vol. 21, no. 3, pp. 756-767, May (2006).

13. P. Zheng, R. Liu, P. Thelin, E. Nordlund, C. Sadarangani, Research on the Parameters and Performances of a 4QT Prototype Machine Used for $H E V$, IEEE Transactions on Magnetics, Jan. 2007 Volume: 43 Issue: 1, pp: 443-446, (2007).

14. A. Cavagnino, M. Lazzari, F. Profumo, A. Tenconi, A Comparison Between the Axial flux and the Radial-flux Structures for PM Synchronous Motors, In Proceedings of IEEE Industry Applications Conference, 36th IAS Annual Meeting, pp. 16111618 (2001). 